\title{
EXECUTION IN SELECTION TASK DEPENDS ON CHRYSIPPUS' CRITERION FOR THE CONDITIONAL
}

\author{
MigUEL LÓPEZ-ASTORGA \\ Institute of Humanistic Studies "Juan Ignacio Molina" \\ University of Talca (Chile), milopez@utalca.cl
}

\begin{abstract}
Wason's selection task is a current cognitive problem. It is a reasoning task including a conditional sentence that only sometimes is correctly solved by participants. It has been claimed that the versions of the task that are often properly executed are only those in which the conditional sentence fulfills the criterion given by Chrysippus of Soli for the conditional. In this paper, this point is checked by considering a relevant number of versions of the aforementioned task in order to review whether or not their conditionals meet Chrysippus' requirement.

KEYWORDS: Ancient logic, Chrysippus of Soli, cognition, conditional, selection task.

* This paper is a result of Project CONICYT/FONDECYT/REGULAR/FOLIO No 1180013, "Recuperación de las formas lógicas de los enunciados a partir de un análisis de las posibilidades semánticas a las que hacen referencia," supported by the National Fund for Scientific and Technological Development (FONDECYT, following its initials in Spanish), Government of Chile. The author also thanks Project "PIA Ciencias Cognitivas, Centro de Investigación en Ciencias Cognitivas, Instituto de Estudios Humanísticos, Universidad de Talca."
\end{abstract}

\section{Introduction}

It has been stated that Chrysippus of Soli already offered important elements to take into account in contemporary cognitive science (e.g., López-Astorga 2017). In particular, it has been said that he provided an account that can help to understand what happens with the different versions of the selection task presented by Wason (e.g., Wason 1966 and 1968). As it is well known, the problem with this task is that it is possible to achieve good results only with some of its versions, and the idea that has been proposed is that the versions that are usually executed correctly are those including a conditional following the criterion given by Chrysippus. Accordingly, the hypothesis is that, if the conditional in a version of Wa- 
son's selection task does not comply Chrysippus' account, the results of that version can only be poor (López-Astorga 2017).

However, this idea needs to be better underpinned. Essentially, it is based upon just two examples discussed in a chapter of book (López-Astorga 2017). So, it is required a more exhaustive study that pays attention to a relevant number of versions of selection task. And, obviously, what such a study must verify is whether or not the relation between the results in the task and Chrysippus' criterion exists indeed.

That is exactly to which this paper aims. To achieve it, first it will explain what the selection task and its difficulties are. Then, the arguments supporting the thesis that the versions of the task with positive results are those with conditionals fulfilling Chrysippus' requirement will be described. And next, an analysis of different versions of the task that are to be found in the literature will be presented. The goal will be, evidently, to review whether or not it can be claimed that the versions correctly executed are generally the ones acceptable under Chrysippus' interpretation of the conditional.

\section{The selection task proposed by Wason and its problems}

It can be said that the main difficulty of selection task is that only some of its versions are usually well executed. It seems that the more abstract versions often give bad results. An example of abstract version can be as follows:

The participants face four cards and a rule with a conditional form. They know that the cards have both numbers and letters, and that, if they see a letter on a card, that very card necessarily shows a number on its hidden side, and vice versa. In this way, the rule is generally akin to this one:

(1) "If there is a $D$ on one side of the card, then there is a 3 on the other side" (Ragni, Kola, \& Johnson-Laird 2017, p. 980; italics in text).

In a version such as this one, the cards generally show, respectively, ' $D$ ', ' $K$ ', ' 3 ', and ' 7 ' (that is at least the version presented by Ragni et al. 2017), and what the participants need to do is to indicate the cards that they must turn to check whether (1) is true. The problem, nevertheless, is that the correct cards are rarely chosen.

As explained in many works in the literature (e.g., those cited above), the proper cards in a version such as this one would be ' $\mathrm{D}$ ' and '7.' That is obvious following both modern propositional logic and Stoic logic. In both of these logics, given that ' $\mathrm{D}$ ' is in the antecedent of (1), to select it is to apply Modus Ponendo 
Ponens. Likewise, given that ' 7 ' is a different number from that appearing in the consequent of (1), to choose it is, again, in both of the mentioned logics, to apply Modus Tollendo Tollens. In Chrysippus' view and, accordingly, following Stoic logic, there is no rule, schema, or indemonstrable justifying to elect ' $\mathrm{K}$ ' or ' 3 .' On the other hand, under current standard propositional logic, it can be stated that, given that ' $\mathrm{K}$ ' is a letter different from the one in the antecedent and ' 3 ' refers to the content of the consequent, to select them is, respectively, to commit the denying the antecedent fallacy and the affirming the consequent fallacy (see, e.g., López-Astorga 2017).

Nonetheless, as said, it is very unusual that people tend to select the correct cards in a version of the task based upon a rule such as (1). However, this circumstance changes when thematic content is incorporated. For instance, when the conditional sentence is similar to the following:

(2) "If you give me some potatoes, then I will give you some corn" (Fiddick, Cosmides, \& Tooby, 2000: 28).

And the cards indicate whether or not potatoes and corn are given, the results significantly improve, since people tend to choose the cards corresponding to Modus Ponendo Ponens and Modus Tollendo Tollens (see also, for an explanation, e.g., López-Astorga 2017).

But this is not that easy, as there are also tasks with thematic content that generally lead to bad results. One clear case can be this one:

(3) "If it's a weekday, then the sun is shining" (Fiddick \& Erlich, 2010: 135).

Obviously, the cards used in a task such as that in which (3) was included refer to facts such as whether or not it is a weekday, or whether or not the sun is shining. However, the important point here is that, in tasks such as this one, the participant does not often elect the right cards (see also, for a further explanation, e.g., López-Astorga 2017). So, there is a problem here, and Chrysippus of Soli appears to have the key to solve it.

\section{Chrysippus of Soli and Wason's selection task}

The proposal that links Chrysippus' thought to Wason's selection task is mainly based upon the criterion offered by the former to interpret the conditional (see, in addition to López-Astorga 2017, e.g., Cicero, De Fato 12, Diogenes Laërtius, Vitae Philosophorum 7, 73, Barnes, Bobzien, \& Mignucci 2008; Gould 1970; O’Toole \& 
Jennings 2004). According to that interpretation, the conditional needs to fulfill a requirement: the negation or denial of the consequent should be inconsistent with the antecedent (to a discussion on what this inconsistency exactly meant in Chrysippus' view and, especially, whether it was empirical or logical, see, e.g., Gould 1970). This clearly moves away from the criterion attributed to Philo of Megara, that is, the material interpretation of classical logic that contemporary propositional calculus assumes (see, e.g., Bocheński 1963; López-Astorga 2019). Nevertheless, the point of the proposal is that, whenever this requirement is followed in a conditional used in a version of selection task, the results with that version usually are optimal (López-Astorga 2017).

In practice, this implies that, if Chrysippus' criterion is fulfilled, the participant can note that a conditional relation really exists between the clauses. Thus, Modus Ponendo Ponens and Modus Tollendo Tollens can be applied, and the wrong cards are ignored (López-Astorga 2017).

In particular, following the proposal (i.e., López-Astorga 2017), it can be claimed that it is normal that (1) leads to poor results. That there is something different from ' 3 ' is not in contradiction to the fact that there is a ' $\mathrm{D}$ ' at once. However, the situation in (2) is distinct. This last sentence was presented by Fiddick et al. (2000) along with a story that spoke about a farmer that wanted to sell potatoes and get corn in return. Hence, in that context, not to get corn was incoherent with giving potatoes, and that can explain its good results. Otherwise, in (3), while there is a thematic content, like in (1), there is no relation between the antecedent and the consequent either, and that is the reason for its incorrect execution (again, in López-Astorga 2017, these explanations are more developed).

But (2) is only an example. It is obvious that to check whether or not the hypothesis is valid, it is necessary to review a greater number of versions of selection task. That is what will be done below, by analyzing a relevant number of versions that are to be found in the literature.

\section{More versions of selection task meeting Chrysippus' criterion}

The following is a list of rules in versions of Wason's selection task that either have led to positive results or have been presented as examples of conditionals with which the execution of the task should be correct. Of course, many of them are parts of broader experiments in which the contexts and even the rules are sometimes manipulated in order to show that the results support the frameworks of the particular experimenters in each case. However, what is interesting here is that, as said, they have in common that they are typical rules that, in general, and 
beyond the particular manipulations in the experiments, can cause excellent results in selection tasks.

In this way, another conditional of this kind fulfilling the requirement given by Chrysippus of Soli (and which is commented on in López-Astorga 2017, as well) is this one:

(4) "If a man eats cassava root, then he must have a tattoo on his face" (Cosmides 1989: 264).

One might not see a relation between the if-clause and the then-clause in (4) at a glance. Nevertheless, as (2), when most participants preferred the right cards, (4) was used together with a story making the negation of its consequent inconsistent with the antecedent. The story described a tribe in which married men had tattoos on their faces, and only they were allowed to eat cassava root, an aphrodisiac with a very strong power. Therefore, eating cassava root without having a tattoo was to break the law, and that meant that the antecedent and the negation of the consequent of the conditional were not admissible at the same time.

However, to find versions of selection task, a very interesting work can be that of Gigerenzer and Hug (1992). This is so because it includes many examples used before. The following are rules indicated in this last paper:

(5) "If you eat duiker meat, then you have found an ostrich eggshell" (Gigerenzer \& Hug 1992: 137).

This sentence also has commonalities with (4). Both of them come from Cosmides (1989) and were used in different versions in which the contexts were manipulated. As in (4), one of those manipulations consisted of a story that made (5) fulfill Chrysippus' criterion, and, in this way, led participants to select the cards related to Modus Ponendo Ponens and Modus Tollendo Tollens. That story told that to get an ostrich eggshell was a very hard task, and that its reward was to eat duiker meat, a delicacy.

The same was done with this sentence:

(6) "If someone stays overnight in the cabin, then that person must bring along a bundle of wood from the valley" (Gigerenzer \& Hug 1992: 142). 
In this case, the context that caused good results provided that bringing wood was a requirement to be allowed to use the cabin. So, the contradiction between the first clause and the negation of the second clause was, once again, obvious.

Something similar is also what happened with this other rule:

(7) "If a student is to be assigned to Grover High School, then that student must live in Grover City" (Gigerenzer \& Hug 1992: 142).

In one of the conditions, whose results were positive, a story caused Chrysippus' criterion to be followed. That story described a circumstance in which the parents living in Grover City were the people supporting Grover High School, and, based upon that, no child from other city should be in that school.

In the same way, the case of (8) was not very different:

(8) "If a player wins a game, then he will have to treat the others a round of drinks at the club's restaurant" (Gigerenzer \& Hug 1992: 146).

For (8), the story leading to the criterion and an optimal selection of cards was very simple. That story just indicated that a club had (8) as a strict rule and it should be respected.

The contextual story enabling the election of the correct cards was clear for this sentence as well:

(9) "If a small-time drug dealer confesses, then he will have to be released" (Gigerenzer \& Hug 1992: 146).

Indeed, the small-time drug dealer was told that, if he gave a confession and some information on big dealers, he could leave.

One more example with a similar structure can be this one:

(10) "If an employee works on the weekend, then that person gets a day off during the week" (Gigerenzer \& Hug 1992: 154).

Actually, one might think that a story developing the idea in (10) is not even necessary, since it refers to an obvious situation in which, if somebody makes the effort to work during the weekend, that person will hope to obtain the reward of a day off (in fact, this aspect was one of the crucial points the experiment tried to show). In any case, when an explanatory context in this direction was included, the results were undoubtedly positive. 
A detailed context does not seem to be necessary in this sentence either:

(11) "If a previous employee gets a pension from a firm, then that person must have worked for the firm for at least ten years” (Gigerenzer \& Hug 1992: 155).

However, as in (10), to offer even further clarification, (11) was also presented, in one condition with an adequate election of cards, along with a story making it evident to a greater extent that it is coherent with Chrysippus' interpretation of the conditional.

Thus, other instance akin to the previous ones is this:

(12) "If a home owner gets a subsidy, then that person must have installed a modern heating system" (Gigerenzer \& Hug 1992: 156).

Given (12) and assuming that it is true, it is not hard to note that a negation of its consequent is incompatible with its antecedent. Nevertheless, a contextual description speaking about an institution monitoring environmental problems was included here as well for a condition with significantly good results.

According to Gigerenzer and Hug (1992), rules such as (12) were very related to real situations in certain countries, such as Germany in that moment. So, just its use in those countries could make them be in accordance with the account given by Chrysippus of Soli. That was the case of this sentence too:

(13) "If an envelope is sealed, then it must have a 1-mark stamp" (Gigerenzer \& Hug 1992: 158).

Anyway, an enlightening story also supported the understanding of (13) in a condition in which the participants tended to choose the cards corresponding to Modus Ponendo Ponens and Modus Tollendo Tollens.

But there are more cases akin to rules such as (10), (11), and (12). This sentence does not appear to require much more explanation:

(14) "If a passanger is allowed to enter the country, then he or she must have had an inoculation against cholera" (Gigerenzer \& Hug 1992: 160).

Certainly, (14) does not seem to need a story of any kind to clarify that it fulfills the criterion provided by Chrysippus. Nevertheless, in a condition with very good 
percentages of selection of cards, a context explaining a relation in that sense between the if-clause and the then-clause was used.

Finally, perhaps it can be stated the same regarding this rule:

(15) "If a customer is drinking an alcoholic beverage, then he or she must be over 18 years old" (Gigerenzer \& Hug 1992: 162).

Most people in most countries know that a legal age to drink exists. So, the relation between the clauses claimed by Chrysippus appears to be guaranteed in (15). Nonetheless, in addition, as in the previous cases, in a condition in which the results were correct, an explanation insisted in that relation.

Maybe another interesting paper presenting examples of rules can be the one of Sydow, Hagmayer, Metzner, and Waldmann (2005). In this paper, it is said that a rule that should cause the selection of the logically correct cards is:

(16) "If you are a bachelor, you must bring fish to the medicine man" (Sydow et al. 2005: 197).

But the most important point about (16) is that it was followed by "...it is forbidden to be a bachelor and not to bring fish to the medicine man" (Sydow et al. 2005: 197), which clearly provides the condition demanded by Chrysippus of Soli.

In this way, another sentence of this type indicated by Sydow et al. (2005) is this one:

(17) "If you are a bachelor, you must not go to the bath house" (Sydow et al. 2005: 197).

As in (16), another statement followed (17): “...forbids that one is a bachelor $(p)$ and one goes to the bath house $(q)$ " (Sydow et al. 2005: 197). Therefore, it is clear that (17) is also a conditional in accordance with Chrysippus' interpretation.

Besides, in an experimental condition with good results, they used a rule such as:

(18) "If someone is bachelor, then he must abduct a virgin from a hostile dangerous tribe" (Sydow et al. 2005: 198).

And Chrysippus' criterion was fulfilled here too because the participants had to imagine that they were those entrusted with the check that (18) was respected in a particular tribe. 
That was exactly the same as the participants should do in the case of this rule, which led to the right cards as well:

(19) "If someone is bachelor, then he is forbidden from fleeing from a battle, which is about to be lost" (Sydow et al. 2005: 198).

Hence, as in (18), the instructions given to the participants guaranteed that (19) were coherent with the demand proposed by Chrysippus.

Lastly, a very illustrative rule can also be one included in the research by Cosmides, Barrett, and Tooby (2010):

(20) "If one is going out at night, then one must tie a small piece of red volcanic rock around one's ankle" (Cosmides et al. 2010: 9010; underlined in text).

In the context of their experimental condition 1, in which the participants tended to select the adequate options, Cosmides et al. (2010) described the situation of a tribe with a rule such as $(20)$, and, given that the part of it that is highlighted shows an activity that people often wish to do (at least that is what was assumed by Cosmides et al. 2010), it can be thought that this last sentence also followed Chrysippus' prescription.

Therefore, eighteen rules $-(2)$ and (4) to (20)- causing people to choose the cards corresponding to Modus Ponendo Ponens and Modus Tollendo Tollens have been analyzed above. That analysis has revealed an important point: all of those sentences fulfill Chrysippus' criterion for the conditional. Accordingly, it can be said that they are pieces of evidence supporting the thesis that the versions of Wason's selection task that are correctly executed are those in which that criterion is followed. Of course, one might think that more examples are to be found in the literature. However, several comments can be made against this objection.

On the one hand, the examples presented have been randomly selected. Probably, they are those that one may find first by using any online search engine, and, if it is possible to come to more rules, they are likely to be very akin to one or some of those collected in the present study. In addition, the number taken into account can be considered to be significant according to a binomial distribution. If, given that eighteen examples of conditional sentences leading to good results have been analyzed, it is assumed that this last number is the number of events, it can be stated the number of successes is also eighteen, since all of those examples refer to sentences in accordance with the requirement provided by Chrysippus of Soli. In this way, as the probability of success is just $1 / 2$ (there are only two possi- 
bilities: either the particular sentence is a conditional under Chrysippus' interpretation or not), it is obvious that $\mathrm{p}=\mathrm{o}(\mathrm{N}=18 ; \mathrm{X}=18)$. So, as stated, the statistical significance seems to be unquestionable.

\section{Conclusions and general discussion}

There is no doubt that Wason's selection task keeps being an important issue nowadays. Relatively recent researches continue to be carried out on it (e.g., Ragni et al. 2017). Nevertheless, if this task is still relevant, it is evident that the different solutions offered to solve its problems are that as well. As shown, one of those solutions can be that based upon Chrysippus' philosophy. Accordingly, following a direction akin to the one proposed in papers such as that of López-Astorga (2017), it can be stated that perhaps it would be suitable that cognitive science paid more attention to philosophical proposals in the past, since, as argued, some of them can have the key to resolve some of the difficulties the studies on cognition face today.

Of course, cognitive science can offer very interesting solutions for selection task at present. Clearly, one of them can be presented by the theory of mental models (e.g., Khemlani \& Johnson-Laird 2019; Ragni et al. 2017). Perhaps this theory has an advantage: in addition to be able to respond to the questions Wason's selection task raises, it can solve a significant number of problems current psychology of reasoning should deal with too. Nonetheless, one might ask to what extent this type of frameworks are totally independent from the criterion offered by Chrysippus.

Indeed, as it has been pointed out (e.g., López-Astorga 2017), a theory such as that of mental models appears to claim that, to properly execute selection task, individuals have to detect all the semantic possibilities related to the rule. However, people do not always recover all of those possibilities, and that is what occurs when the results of the task are poor. So, if this view of the theory of mental models is correct, when the cards chosen are those for an appropriate application of both Modus Ponendo Ponens and Modus Tollendo Tollens, individuals note all the semantic possibilities valid for the rule. But, undoubtedly, if there is a meaning connection such as the one required by Chrysippus between the antecedent and the consequent of the conditional, the likelihood of a participant discovering all the semantic possibilities corresponding to that conditional is much higher.

In this light and beyond the validity Chrysippus' particular proposal can have for difficulties linked to other aspects of human cognition, it seems to be necessary to review linguistic, epistemological, and logical analyses coming from ancient times. The aim of these reviews would be to check the potential of those 
analyses to solve or help to solve to some extent contemporary cognitive problems. The case of Chrysippus of Soli and Wason selection task appears to be obvious from the arguments above. However, there are both much more approaches in the ancient philosophical thought and much more difficulties to solve in current cognitive science.

\section{REFERENCES}

Barnes, J., Bobzien, S., \& Mignucci, M. (2008) “Logic," in K. Algra, J. Barnes, J. Mansfeld, \& M. Schofield, eds. The Cambridge History of Hellenistic Philosophy. Cambridge, UK: 77-225.

Bocheński, I. M. (1963) Ancient Formal Logic. Amsterdam.

Cosmides, L. (1989) "The logic of social exchange: Has natural selection shaped how humans reason? Studies with the Wason selection task," Cognition 31, 187-276.

Cosmides, L., Barrett, H. C., \& Tooby, J. (2010) "Adaptive specializations, social exchange, and the evolution of human intelligence," Proceedings of the National Academy of Sciences 107, 9007-9014.

Fiddick, L. \& Erlich, N. (2010) "Giving it all away: Altruism and answers to the Wason selection task," Evolution and Human Behavior 31, 131-140.

Fiddick, L., Cosmides, L., \& Tooby, J. (2000) "No interpretation without representation: The role of domain-specific representations and inferences in the Wason selection task," Cognition 77, 1-79.

Gigerenzer, G. \& Hug, K. (1992) "Domain-specific reasoning: Social contracts, cheating, and perspective change," Cognition 43, 127-171.

Gould, J. B. (1970) The Philosophy of Chrysippus. Albany, NY.

Khemlani, S. \& Johnson-Laird, P. N. (2019) “Why machines don't (yet) reason like people," Künstliche Intelligenz 33, 219-228.

López-Astorga, M. (2017) “Chrysippus' logic and Wason's selection task," in P. Hanna, ed. An Anthology of Philosophical Studies. Volume 11. Athens, Greece: 47-56.

López-Astorga, M. (2019) "The semantic method of extension and intension and the four criteria of the conditional described by Sextus Empiricus," Revista de Filosofia 44(2), 253-261.

O'Toole, R. R. \& Jennings, R. E. (2004) “The Megarians and the Stoics," in D. M. Gabbay \& J. Woods, eds. Handbook of the History of Logic, Volume 1. Greek, Indian and Arabic Logic. Amsterdam, The Netherlands: 397-522.

Ragni, M., Kola, I., \& Johnson-Laird, P. N. (2017) "The Wason selection task: A metaanalysis," in G. Gunzelmann, A. Howes, T. Tenbrink, \& E. J. Davelaar, eds. Proceedings of the $32^{\text {nd }}$ Annual Conference of the Cognitive Science Society. Austin, TX: 980985 .

Sydow, M. von, Hagmayer, Y., Metzner, N., \& Waldmann, M. R. (2005) "Cooperation detection and deontic reasoning in the Wason selection task," in K. Opwis \& I.-K. 
Penner, eds. Proceedings of KogWiso5. The German Cognitive Science Conference 2005. Basel, Switzerland: 195-200.

Wason, P. C. (1966) "Reasoning," in B. Foss, comp. New Horizons in Psychology. Harmondsworth (Middlesex), UK: 135-151.

Wason, P. C. (1968) "Reasoning about a rule," Quarterly Journal of Experimental Psychology $20,273-281$. 